\title{
Hydromagnetic Natural Convection Heat Transfer of Copper- Water Nanofluid within a Right-Angled Triangular Cavity
}

\author{
Tarikul Islam $^{1}$, Nazma Parveen ${ }^{2}$, Md. Fayz-Al-Asad ${ }^{3}$ \\ ${ }^{1}$ Department of Mathematics, Bangabandhu Sheikh Mujibur Rahman Science and Technology \\ University, Gopalganj-8100, Bangladesh. \\ ${ }^{2}$ Department of Mathematics, Bangladesh University of Engineering and Technology, Dhaka-1000, \\ Bangladesh. \\ ${ }^{3}$ Department of Civil Engineering, Dhaka International University, Dhaka, Bangladesh.
}

Received: June 20 2020; Received in revised form: 10 August; Accepted: 16 August 2020; Published online 18 August 2020

(C) Published at www.ijtf.org

\begin{abstract}
This investigation on free convection flow and temperature transfer within a right-angled triangular cavity loaded uniformly by $\mathrm{Cu}-\mathrm{H}_{2} \mathrm{O}$ nanofluid including heated boundary conditions at horizontal side is performed numerically. The standing side is cooled at low heat while the hypotenuse of the triangular is insulated. The governing non-dimensional highly non-linear partial differential equations are performed by employing Galerkin weighted residual finite element method. The simulated numerical findings are exhibited using streamline contours, isotherm contours and average Nusselt number for the sampling parameters named nanoparticles volume fraction, Rayleigh number, and Hartmann number. The outcome demonstrates temperature transfer value reduces for the enhancement of Hartman number whereas improve significantly for the increase of buoyancy driven parameter Rayleigh number. Also, an excellent average temperature transfer is observed for uniform heated boundary condition (case I) compared to non-uniform thermal boundary conditions (case II \& case III).
\end{abstract}

Keywords: Hydromagnetic, FEM, Nanofluids, Right-angled Triangular cavity, Free convection.

\section{Introduction:}

Natural convective flowing and temperature disposal into a triangle shape enclosure charged by nanofluids have an immeasurable real life enrollments in numerous industrial systems, engineering, and domestic process like home ventilation systems, fire prevention, heat exchangers, solar collectors, geothermal reservoirs, refrigeration units etc. Choi [1] 
Tarikul Islam et al.

International Journal of Thermofluid Science and Technology (2020), Volume 7, Issue 3, Paper No. 070304

investigated about the technology of nanofluid for the current and future research.

Buongiorno

\begin{tabular}{|c|c|c|c|}
\hline \multicolumn{4}{|c|}{ Nomenclature } \\
\hline$a$ & wave amplitude (m) & \multicolumn{2}{|c|}{ Greek symbols } \\
\hline$B_{0}$ & magnitude of magnetic field & $\alpha$ & thermal diffusivity $\left(\mathrm{m}^{2} \mathrm{~s}^{-1}\right)$ \\
\hline $\begin{array}{l}c_{p} \\
\left(\mathrm{k}^{-1}\right)\end{array}$ & specific heat at constant pressure $\left(\mathrm{JKg}^{-1} \mathrm{k}^{-1}\right)$ & $\beta$ & thermal expansion coefficient \\
\hline$g$ & gravitational acceleration $\left(\mathrm{ms}^{-2}\right)$ & $\phi$ & solid volume fraction \\
\hline$H a$ & Hartmann number & $\mu$ & dynamic viscosity $\left(\mathrm{kg} \mathrm{m}^{-1} \mathrm{~s}^{-1}\right)$ \\
\hline$k$ & thermal conductivity $\left(\mathrm{Wm}^{-1} \mathrm{k}^{-1}\right)$ & $v$ & kinematic viscosity $\left(m^{2} s^{-1}\right)$ \\
\hline$L$ & length of the enclosure & $\theta$ & non-dimensional temperature \\
\hline$N u_{a v}$ & average Nusselt number & $\rho$ & density $\left(\mathrm{kg} \mathrm{m}^{-3}\right)$ \\
\hline$p$ & dimensional pressure $\left(\mathrm{kg} \mathrm{m}^{-1} s^{-2}\right)$ & $\sigma$ & electric conductivity \\
\hline$P$ & dimensionless pressure & $\psi$ & stream function \\
\hline $\operatorname{Pr}$ & Prandtl number & \multicolumn{2}{|c|}{ Subscript } \\
\hline$R a$ & Rayleigh number & $h$ & heat surface \\
\hline$T$ & fluid temperature $(K)$ & $c$ & cold surface \\
\hline$u, v$ & velocity components $\left(\mathrm{ms}^{-1}\right)$ & $f$ & fluid \\
\hline$U, V$ & dimensionless velocity component $\left(\mathrm{ms}^{-1}\right)$ & $n f$ & nanofluid \\
\hline$x, y$ & coordinates $(\mathrm{m})$ & $s$ & nanoparticle \\
\hline$X, Y$ & non-dimensional coordinates & $b f$ & base fluid \\
\hline
\end{tabular}

[2] investigated convective mass and heat transportation in nanofluids. Aydin et al. [3] performed free convection where the rectangular enclosure is warmed-up from one part and consoled from the roofing. Ghassemi et al. [4] investigated numerically natural convectional temperature disposal as well as liquid flowing into the triangle shape enclosure. Varol, Oztop, and Yilmaz [5] researched natural convective across the protruding isothermal cooker into a triangular enclosures. Holtzman et al. [6] performed laminar spontaneous convection into a triangular cavities having two sides of equal length warmed from beneath whereas consoled from above. Das et al. [7] studied about the applications of nanofluids from various aspects in science and technology. Roy et al. [8] studied about the finite element simulation within triangle shape cavity upon the free convective on account of uniformly heater as well as nonuniformly heater on lower side. FEM analysis for free convective flowing into an isosceles triangle shape chamber containing an identical as well as non-uniform thermal systems was researched by Basak, Roy, Babu, and Balakrishnan [9]. Free convection laminar flow into isosceles triangle shape cavity for cooled horizontal and warmed-up bended walls was performed by Kent [10]. Kamiyo et al. [11] investigated comprehensively respecting free convective flowing within triangular enclosures.

To augment the rate of temperature transfer by using nanofluids are engaged significantly in the recent years. Various sampling of nanoparticles such as $\mathrm{Al}_{2} \mathrm{O}_{3}, \mathrm{Fe}_{3} \mathrm{O}_{4}, \mathrm{Cu}$ and $\mathrm{TiO}_{2}$ are accessible commercially and employed effectively for the augmentation of 
Tarikul Islam et al.

International Journal of Thermofluid Science and Technology (2020), Volume 7, Issue 3, Paper No. 070304

temperature disposal. Real life appliance of nanofluids for the presence and posterior research was investigated by Wong et al. [12]. Natural convection time dependent study into a triangular cavity taking isothermal heating was investigated by Saha [13]. Aydin et al. [14] performed about natural convection using heated and consoled adjoining walls into a quadrantal cavity. Walid et al. [15] investigated about buoyancy force on temperature transfer and fluid flowing within a prismatical enclosure. Mixed convection flowing within a wavy triangular chamber loaded with nanofluid taking viscosity models was investigated by Nasrin et al. [16]. Khanafer and Aithal [17] performed about laminar combined convective characteristics within the enclosure. Yesiloz and Aydin [18] researched regarding laminar convective flow into right-angled triangle shape cavity using a thermal and cooled neighboring walls. Usual convective temperature disposal including entropy generation within a triangle shape cavity was researched by Bhardwaj and Dalal [19]. Suvash and Gu [20] researched about free convectional flowing within triangle shape cavity that warmed-up from below. Mirabedin [21] investigated related to CFD modeling of fee convection into triangle shape cavity. Triveni, Panua, and Sen [22] researched about the impacts of cooled wall in different position on free convective flowing within triangle shape enclosure. Boulahia et al. [23] studied respecting combined convection temperature disposal of nanofluid within an enclosure using various triangle shape warming obstacles. Rahman et al. [24] studied in regarding to MHD usual convective temperature flow within isosceles triangle shape cavity charged by nanofluid. Very recently, Siddiqui and Turkyilmazoglu investigated about free convective heat transfer of ferrofluid within a permeable cavity. They conclude that average rate of heat transfer is higher at left wall for the increment of Lorentz force inuced by Hartmann number.

This current research is investigated for exploring the convective flowing as well as temperature transfer within right-angled triangle shape cavity charged by $\mathrm{Cu}-\mathrm{H}_{2} \mathrm{O}$ nanofluid for three distinct heating boundary conditions. The influence of sampling parameters named Rayleigh number, nanoparticles volume fraction, and magnetic field parameter are numerically performed and expound them from physical point of scene.

\section{Problem Formulation:}

\section{Physical Model:}

A schematic spectacle of a right-angled triangle shape chamber including necessary boundary conditions and coordinates for the current research is exhibited in Fig. 1. 


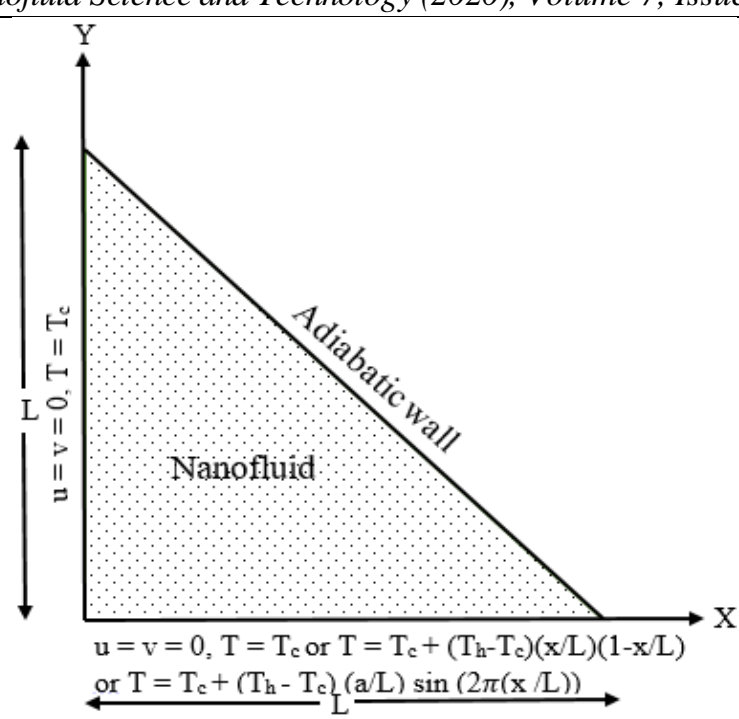

Fig. 1: Schematic spectacle of right-angled triangle enclosure.

The length of the both perpendicular and horizontal walls is $L$. The standing wall of the triangle shape cavity is cooled on low heat $T=T_{c}$, while the inclined side is insulated. The horizontal wall is warmed-up at uniformly $T=T_{h}$, parabolically $T=T_{c}+\left(T_{h}-T_{c}\right)\left(\frac{x}{L}\right)\left(1-\frac{x}{L}\right)$ and sinusoidally $T=T_{c}+\left(T_{h}-T_{c}\right)\left(\frac{a}{L}\right) \sin (K x)$. The enclosure is filled with $\mathrm{Cu}-\mathrm{H}_{2} \mathrm{O}$ nanofluid where water $\left(\mathrm{H}_{2} \mathrm{O}\right)$ is taken as base fluid and copper $(\mathrm{Cu})$ as nanoparticles. $B_{0}$ the uniform magnetic field that is assigned within the enclosure towards horizontal direction. A gravitational acceleration force $g=(0, \mathrm{~g})$ is also functioned to downward approach towards the $y$-axis. The nanofluid is predicted as viscous, and incompressible. The two dimensional time independent flow is also processed as laminar. Every rigid boundaries are accepted as no slip walls.

\section{Mathematical Model:}

The governing nonlinear PDEs of aforementioned consideration are figured as follow for Cartesian co-ordinate system in the dimensional appearance (see Tiwari and Das [26], and Boungiorno [2]):

$$
\begin{aligned}
& \frac{\partial u}{\partial x}+\frac{\partial v}{\partial y}=0 \\
& u \frac{\partial u}{\partial x}+v \frac{\partial u}{\partial y}=-\frac{1}{\rho_{n f}} \frac{\partial p}{\partial x}+\frac{\mu_{n f}}{\rho_{n f}}\left(\frac{\partial^{2} u}{\partial x^{2}}+\frac{\partial^{2} u}{\partial y^{2}}\right) \\
& \rho_{n f}\left(u \frac{\partial v}{\partial x}+v \frac{\partial v}{\partial y}\right)=-\frac{\partial p}{\partial y}+\mu_{n f}\left(\frac{\partial^{2} v}{\partial^{2} x}+\frac{\partial^{2} v}{\partial^{2} y}\right)+(\rho \beta)_{n f} \mathrm{~g}\left(T-T_{c}\right)-\sigma B_{0}{ }^{2} v \\
& u \frac{\partial T}{\partial x}+v \frac{\partial T}{\partial y}=\alpha_{n f}\left(\frac{\partial^{2} T}{\partial^{2} x}+\frac{\partial^{2} T}{\partial^{2} y}\right)
\end{aligned}
$$




\section{Boundary conditions:}

For the current problem, the boundary conditions of flow and temperature are listed as:

On the horizontal wall $(y=0,0 \leq x \leq L)$ :

$$
\begin{aligned}
& \text { case I : } u=0, v=0, T=T_{h} \\
& \text { case II : } u=v=0, T=T_{c}+\left(T_{h}-T_{c}\right)\left(\frac{x}{L}\right)\left(1-\frac{x}{L}\right) \\
& \text { case III: } u=v=0, T=T_{c}+\left(T_{h}-T_{c}\right)\left(\frac{a}{L}\right) \sin (K x)
\end{aligned}
$$

On the perpendicular wall: $(\mathrm{x}=0,0 \leq y \leq L) \quad u=0, v=0, T=T_{c}$

On the inclined wall: $(0 \leq x \leq L$ and $0 \leq y \leq L) \quad u=0, v=0, \frac{\partial T}{\partial x}=0$

\section{Dimensional Analysis:}

For reducing the above governing partial differential equations (1)-(4) including boundary conditions (5a)-(5e) into non-dimensional appearance, we preface the subsequent transformational variables:

$$
\begin{aligned}
& X=\frac{x}{L}, Y=\frac{y}{L}, U=\frac{u L}{\alpha_{b f}}, V=\frac{v L}{\alpha_{b f}}, P=\frac{p L^{2}}{\rho_{n f} \alpha_{b f}^{2}}, \theta=\frac{T-T_{c}}{T_{h}-T_{c}}, R a=\frac{g \beta_{b f}\left(T_{h}-T_{c}\right) L^{3}}{v_{b f} \alpha_{b f}}, \\
& H a=B_{o} L \sqrt{\sigma_{b f} / \mu_{b f}}, \text { and } \operatorname{Pr}=\frac{v_{b f}}{\alpha_{b f}}
\end{aligned}
$$

Using these dimensionless variables, governing dimensional equations (1)-(4) may be composed as:

$$
\begin{aligned}
& \frac{\partial U}{\partial X}+\frac{\partial U}{\partial Y}=0 \\
& U \frac{\partial U}{\partial X}+V \frac{\partial U}{\partial Y}=-\frac{\rho_{b f}}{\rho_{n f}} \frac{\partial P}{\partial X}+\operatorname{Pr}\left(\frac{\rho_{b f}}{\rho_{n f}}\right)\left(\frac{\partial^{2} U}{\partial X^{2}}+\frac{\partial^{2} U}{\partial Y^{2}}\right) \\
& U \frac{\partial V}{\partial X}+V \frac{\partial V}{\partial Y}=-\frac{\rho_{b f}}{\rho_{n f}} \frac{\partial P}{\partial Y}+\operatorname{Pr}\left(\frac{\rho_{b f}}{\rho_{n f}}\right)\left(\frac{\partial^{2} V}{\partial^{2} X}+\frac{\partial^{2} V}{\partial^{2} Y}\right)+\frac{(\rho \beta)_{n f}}{\rho_{n f} \beta_{b f}} \operatorname{RaPr} \theta-\frac{\rho_{b f}}{\rho_{n f}} \frac{\sigma_{n f}}{\sigma_{b f}} \operatorname{Ha}^{2} \operatorname{Pr} V \\
& U \frac{\partial \theta}{\partial X}+V \frac{\partial \theta}{\partial Y}=\left(\frac{\alpha_{n f}}{\alpha_{b f}}\right)\left(\frac{\partial^{2} \theta}{\partial^{2} X}+\frac{\partial^{2} \theta}{\partial^{2} Y}\right)
\end{aligned}
$$

On the perpendicular wall: $(\mathrm{X}=0,0 \leq Y \leq 1) U=V=0, \theta=0$

On the horizontal wall $(\mathrm{Y}=0,0 \leq X \leq 1)$ :

case I: $U=V=0, \theta=1$

case II: $U=V=0, \theta=X(1-X)$ 
Tarikul Islam et al.

International Journal of Thermofluid Science and Technology (2020), Volume 7, Issue 3, Paper No. 070304

case III: $U=V=0, \theta=A \sin (2 \pi X)$

On the inclined wall: $(0 \leq X \leq 1$ and $0 \leq Y \leq 1) \quad U=V=0, \frac{\partial \theta}{\partial X}=0$

Average Nusselt number along horizontal warmed-up wall of the cavity is performed as: $N u_{a v}=-\left(\frac{k_{n f}}{k_{b f}}\right) \int_{0}^{1} \frac{\partial \theta}{\partial Y} d X$

\section{Computational Procedure:}

The dimensionless governing non-linear PDEs (7)-(10) including equations (11a)-(11e) are composed using powerful PDE solver Galerkin weighted residual finite element analysis. Zienkiewicz and Taylor [27] discussed in details of this method is well in the textbook. The domain of the solution is discretized within limited number of grids firstly that are determined from non-uniform three cornered elements in this method. A triangular components of six node is exercised for the improvement to the finite element equations. The Galerkin weighted residual method is appointed into the integral equations which are transformed from the dwelling partial differential equations. Integral parts of these equations are accomplished employing Gauss's quadrature technique ([27]). Thereafter, boundary conditions are also employed to modify the non-linear algebraical equations. For solving these algebraical equations in matrix form, Newton-Raphson iteration is devoted. The numerical solution procedure was maintained until the necessary convergent inference along with error estimation as $\left|\Gamma^{n+1}-\Gamma^{n}\right| \leq 10^{-5}$, whereas $\Gamma$ represents subordinate variables $U, V, \theta$ and $n$ represents iteration number.

\section{Grid Independence Experiment:}

On account of engage a grid self-reliant, a comprehensive mesh testing action is employed into the right-angled triangular shaped enclosure for the present problem when $R a=10^{5}, H a=10, \phi=0.04$, and $n=3$. Non-uniform five distinct grid systems are examined such as normal, fine, finer, extra fine, and extremely fine consisting elements number into the resolution field: 1191, 1759, 5025, 13333 and 16745. For the present problem, the numerical procedure is performed using average Nusselt number $\left(N u_{a v}\right)$ of aforesaid elements to checking the development of the fineness of grid is displayed in Fig. 2. The elements size 13333 depicts an ordinary variety in outcomes than other elements for the present study. Therefore, elements 13333 is used for grid independent solution. 


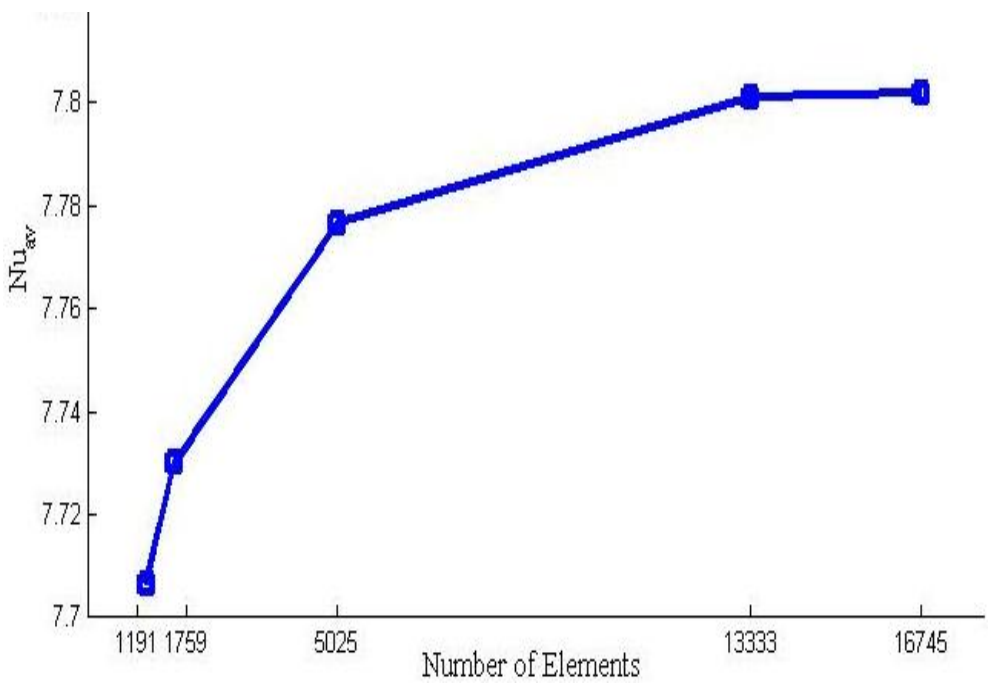

Fig. 2. Average Nusselt number $\left(N u_{a v}\right)$ for various elements.

\section{Validation of Code:}

In order to verify the present numerical scheme, the outcomes from the present code (bottom row) is compared using streamlines and isotherms by means of Gurkan Yesiloz et al. [28] (top row) when $R a=10^{4}$ which is shown in Figure 3. The outcomes prepared by the current code represents strong willingness and support the dependence for using current numerical scheme.
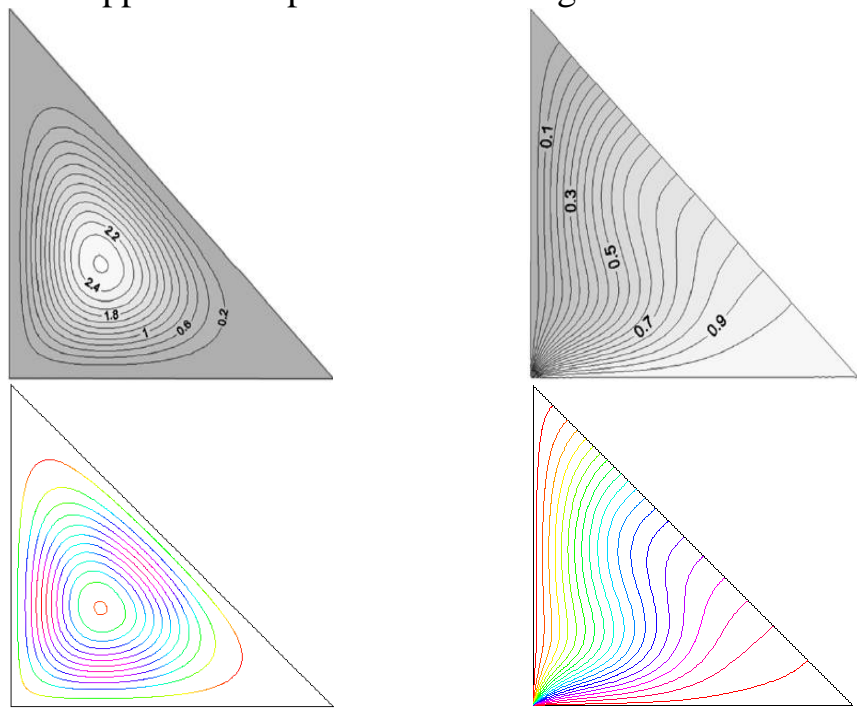

Fig. 3: Adjudgement of streamline contours and isotherm contours between current outcomes (bottom) and Yesiloz and Aydin [28] (top) when $R a=10^{4}$.

\section{Outcomes and Discussion:}

Here, we appeared the outcomes from present numerical scheme finite element analysis for the convective flowing and heat transfer using $\mathrm{Cu}-\mathrm{H}_{2} \mathrm{O}$ nanofluids in the right- 
Tarikul Islam et al.

International Journal of Thermofluid Science and Technology (2020), Volume 7, Issue 3, Paper No. 070304

angled triangle shape cavity of varying updraft three distinct heated boundary conditions. The numerical outcomes of current study have been discussed for various model parameters entitled the Rayleigh number $(R a)$, nanoparticles volume fraction of $(\phi)$ and Hartmann number $(\mathrm{Ha})$ in flowing domain as well as temperature flow characteristics employing isotherm contours, streamline contours and average Nusselt number. Dimension-less amplitude of sinusoidal wave is taken $A=1$ throughout the calculation. The non-appearance values for the parameters are $\phi=0.04, \operatorname{Pr}=6.8377, n=3, R a=10^{5}$, and $H a=10$.

\section{Impact of Rayleigh Number:}

Figure 4 depicts the outcomes of the Rayleigh number $\left(R a=10^{4}, 10^{5}, 10^{6}, 10^{7}\right)$ with fixed $\phi=0.04, H a=10$ on streamlines for three different (Case I, Case II, Case III) updraft thermal boundary conditions. For low $R a\left(=10^{4}\right)$, the result shows that the streamline contours become smooth and the streamlines are little unbiased by the particles of the nanofluid, although they are heated by the uniform heated system and non-uniform heated system that is a good indication of strong conduction. But in case III, a secondary vortex is created near the vertical cold wall. As increases $R a\left(\geq 10^{5}\right)$, the fluid within the enclosure is more and more distorted caused by the heat transfer in that region quickly by convection in case I and case II. In case II, because of non-uniform warming on horizontal wall, a tiny shape cell is discernible on the right corner near horizontal wall within the enclosure concerning the strong buoyancy influence. Furthermore, for the increases of buoyancy driven parameter, the

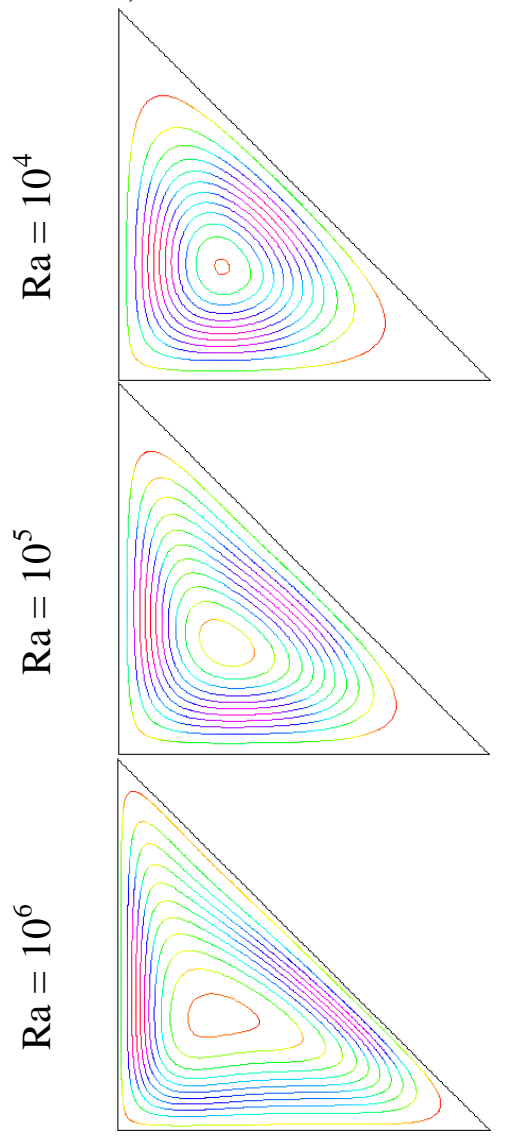

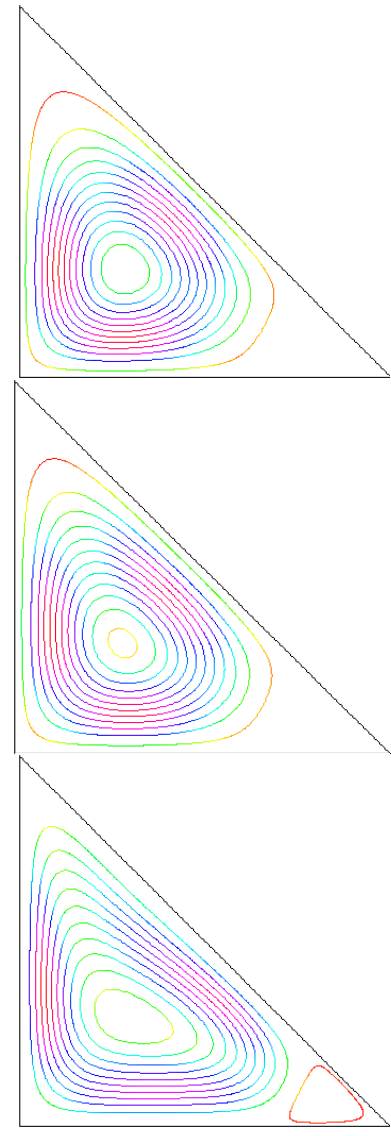

8

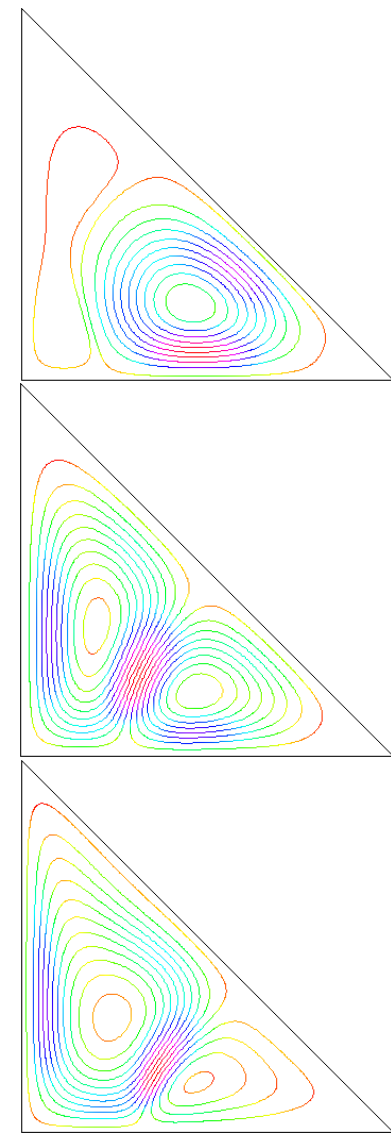



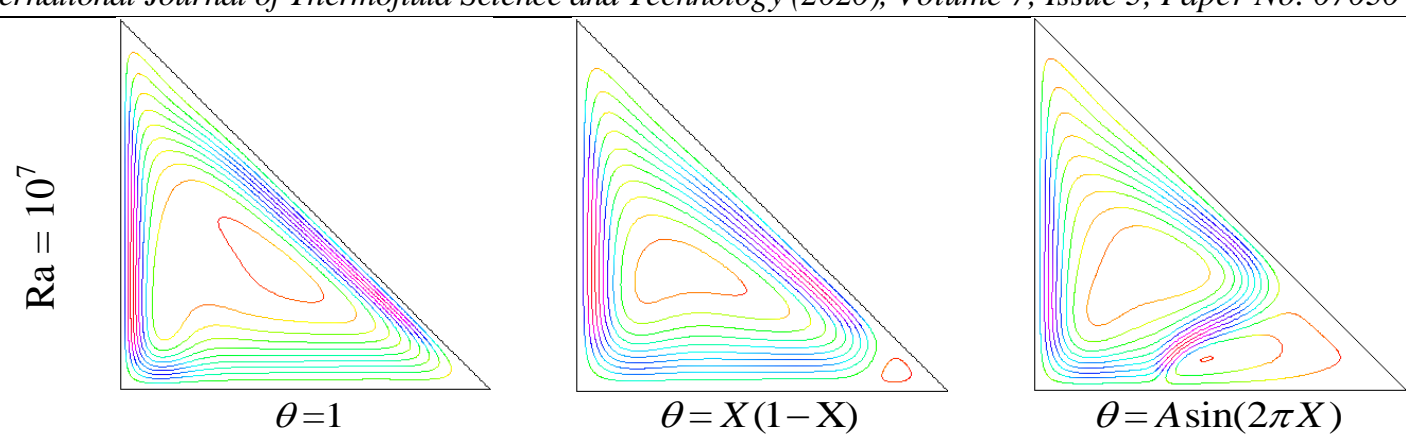

Fig. 3: Outcome of $R a$ on streamlines for three various heated boundary conditions with fixed $\phi=0.04$ and $H a=10$.

denseness and power of the vortex within the cavity increases which turns near the streamlines to each other by the virtue of the dominance of the free convection. For case-III, for increases $R a\left(\geq 10^{5}\right)$, two vortices of streamlines is created at the adjoining horizontal warmed-up and standing cooled walls. The strength of streamlines enhances for the increase of the buoyancy driven parameter that announces the leading temperature flow form convection. Therefore, convection is the leading mode of heat transfer at upper values of $R a$.

The isotherms contours is extremely useful to measure the proficiency of heat transfer in $\mathrm{Cu}-\mathrm{H}_{2} \mathrm{O}$ nanofluid and visualized the conductive to convective style of temperature transfer. Fig. 5 demonstrates the influence of Rayleigh number ( $R a=10^{4}, 10^{5}, 10^{6}, 10^{7}$ ) with fixed $\phi=0.04$, on isotherms for three various updraft heated boundary conditions.
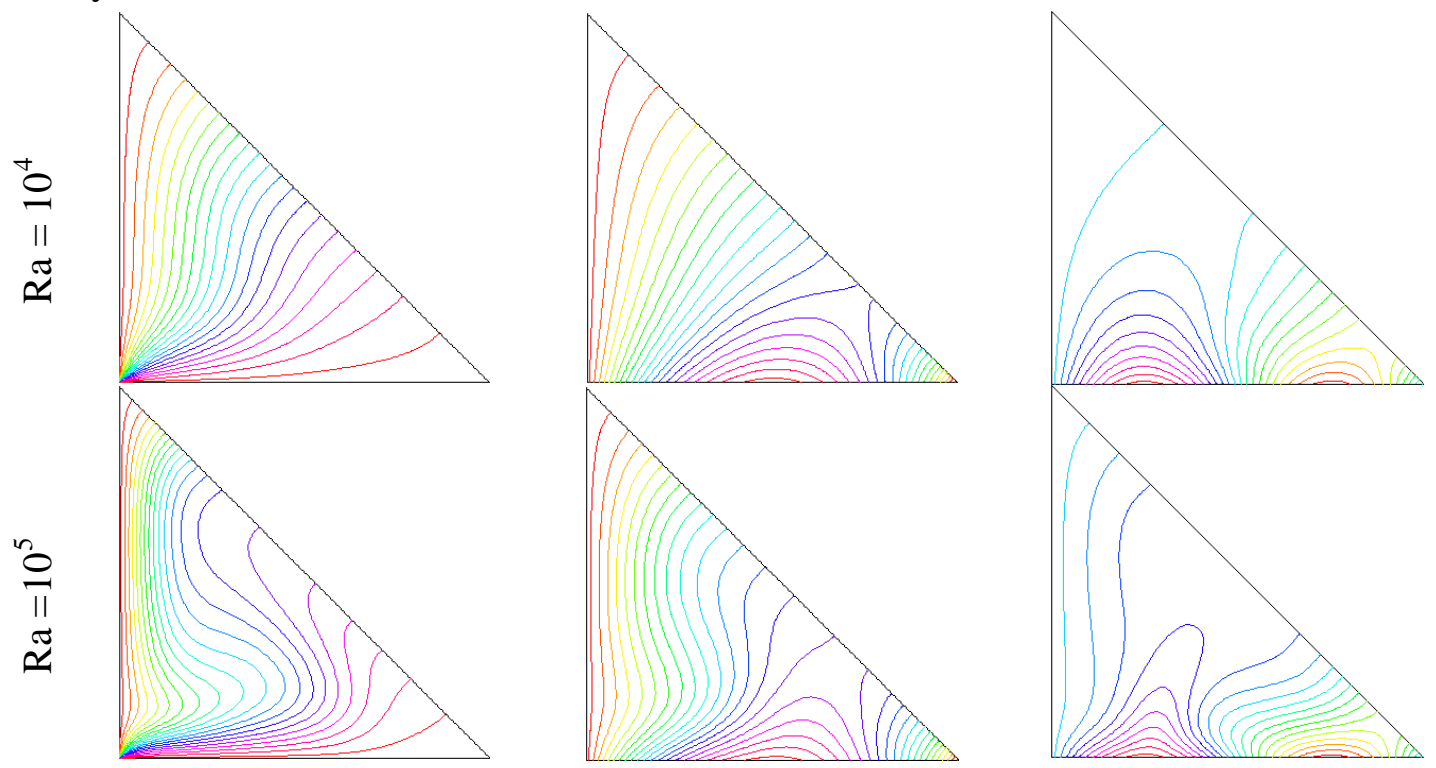
Tarikul Islam et al.

International Journal of Thermofluid Science and Technology (2020), Volume 7, Issue 3, Paper No. 070304
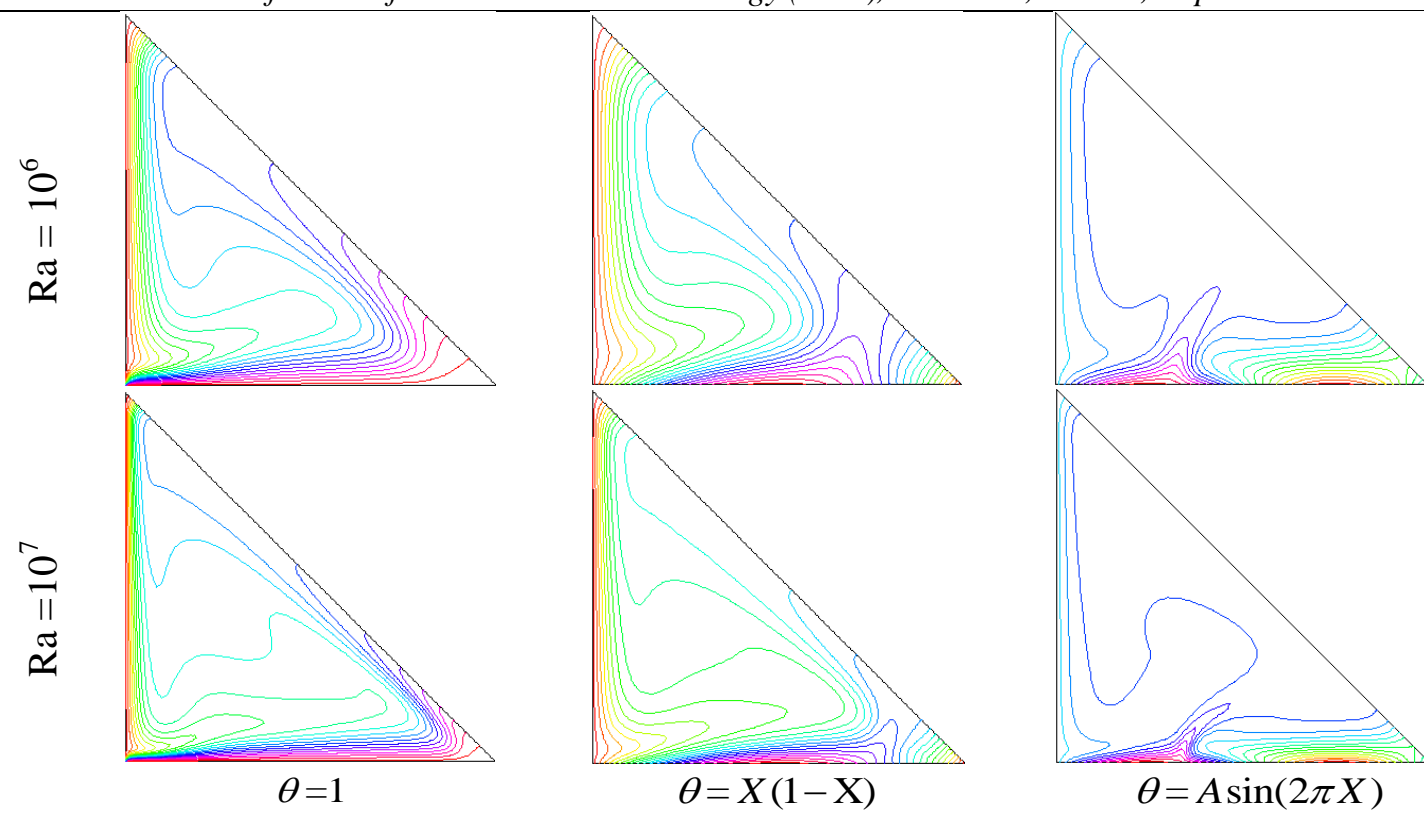

Fig. 5: Outcome of $R a$ on isotherms for three various heated boundary conditions with fixed $\phi=0.04$ and $H a=10$.

These figures also depicture that the streamlines are superfluous compressed neighbor the horizontal hot wall within enclosure for conduction style of heat transfer. The compactness of the isotherm contours diminish on middle within enclosure by upper $R a$, which introduce a powerless mode of temperature transfer. In case I, for uniformly heated boundary condition, the figures depict that there is a measureable discontinuity of temperature distribution at the connection point of horizontal hot and perpendicular cold walls. This is mathematically known as singularity but the fluid temperature will be converged towards the average value of the temperatures of horizontal warmed and perpendicular cooled walls in reality. Thus, left-hand ground corner of enclosure is average value of temperatures in the present study. On the other hand, the implication of the thermal singularity is eliminated for non-uniform heated boundary conditions (case I \& case II), as observed with this figures. For case II, nonuniformly warming
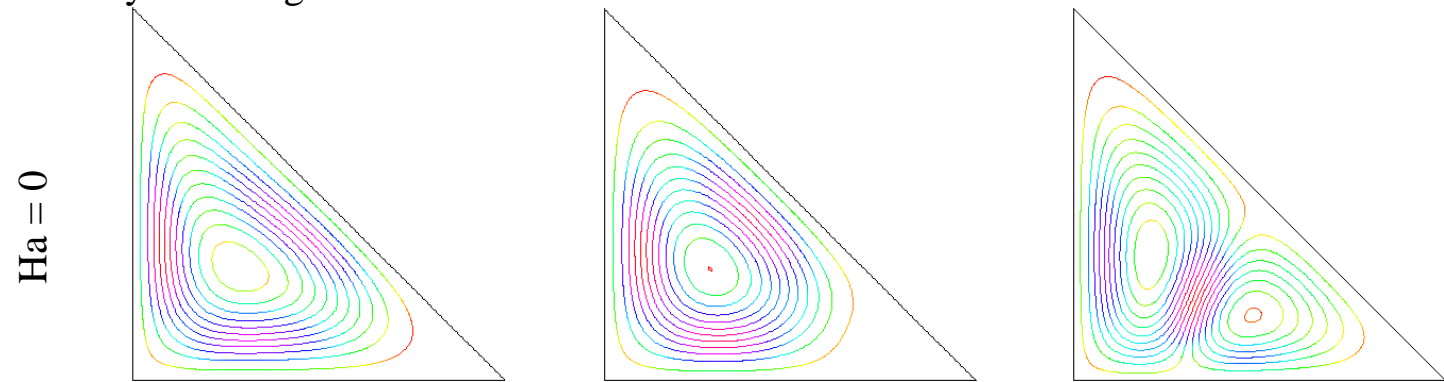

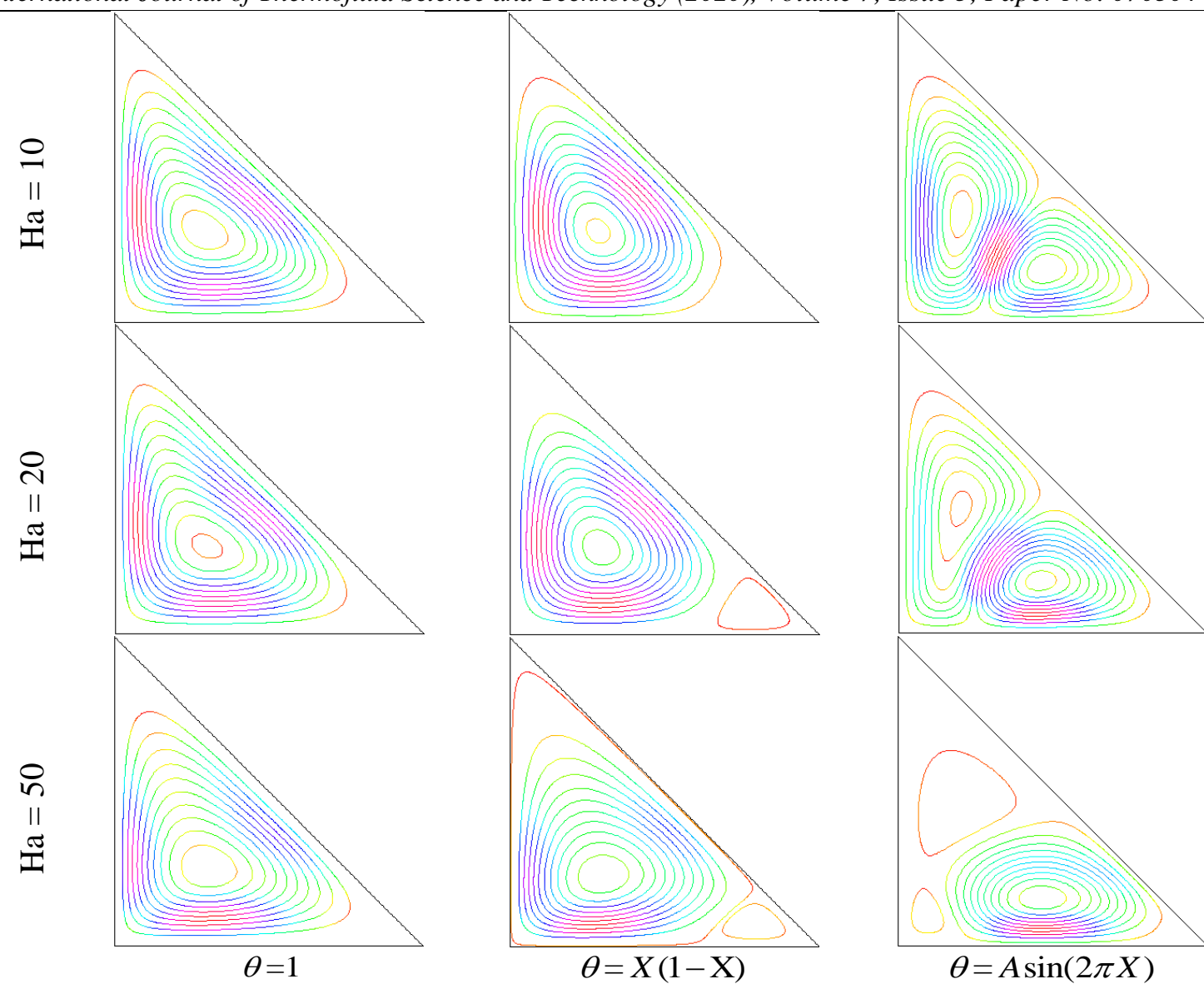

Fig. 6: Outcome of Hartmann number on streamlines for three various heated boundary conditions for fixed $\phi=0.04$ and $R a=10^{5}$.

on horizontal wall, for minor $R a$, the isotherm contours are parabolic in shape neighbor the horizontal wall because of the conduction. But as $R a\left(\geq 10^{5}\right)$ enhances, the compactness and vortex power within enclosure enhances for the influence of the free convection. For case-III, non-uniformly warmed horizontal wall, two symmetric cells of isotherms are formed because of potential conduction neighbor horizontal warmed-up wall. As increases $R a$, the isotherm lines are closely packed neighbor the horizontal hot wall which indicates that the working of a heated boundary veil on the horizontal wall, where conduction be the master type of temperature flowing. In total, temperature disposal rate enhances for the augmentation of Rayleigh number $(R a)$ for all three distinct heated boundary conditions due to the potential convection mode of temperature distributions.
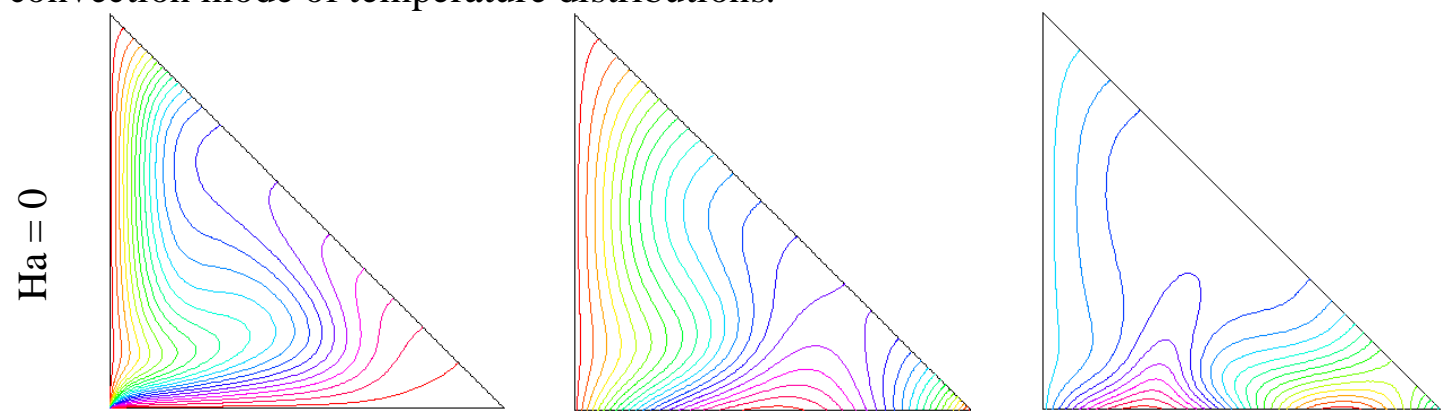
Tarikul Islam et al.

International Journal of Thermofluid Science and Technology (2020), Volume 7, Issue 3, Paper No. 070304
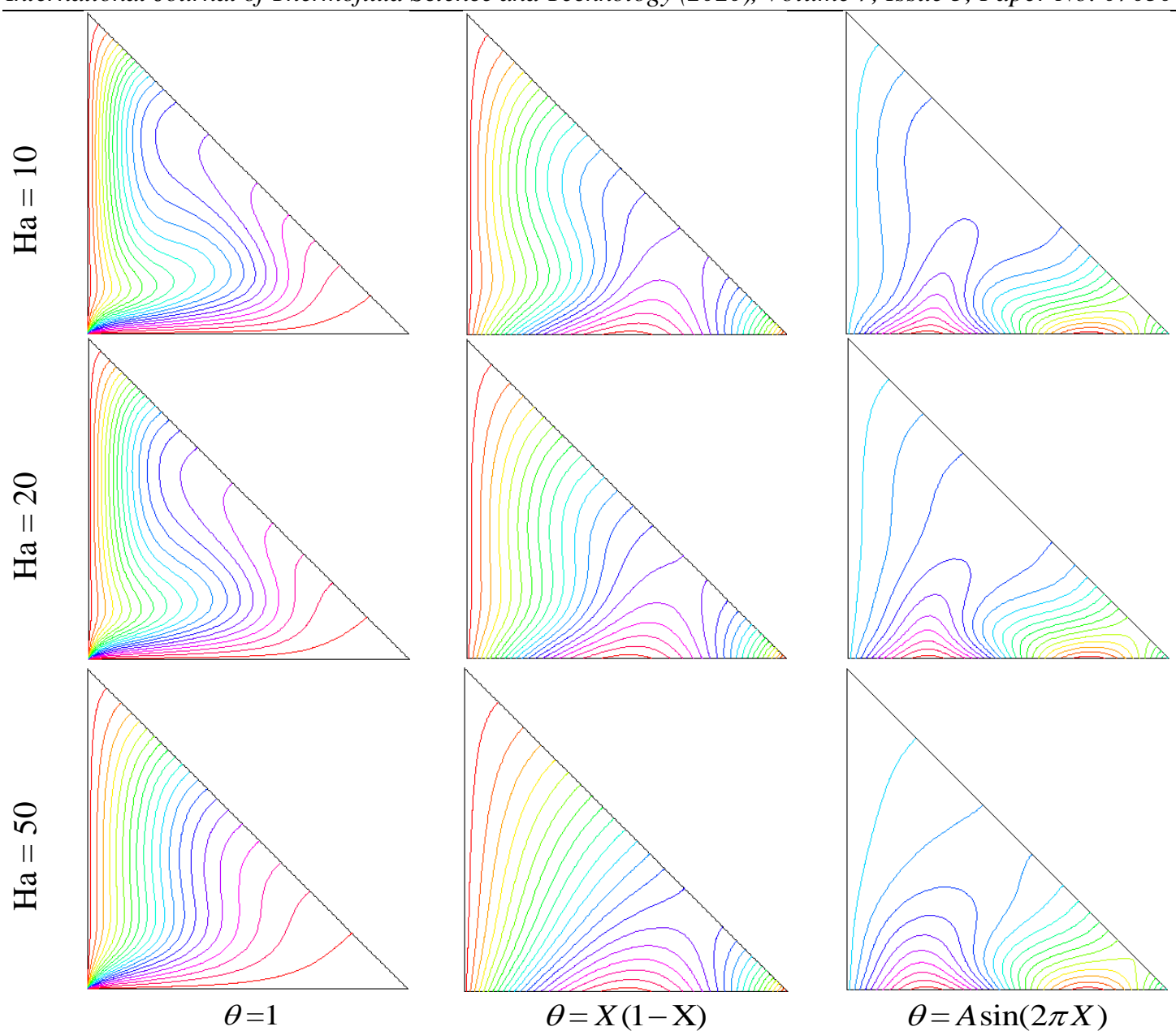

Fig. 7: Outcome of $H a$ on isotherm contours for three various thermal boundary conditions with fixed $R a=10^{5}$ and $\phi=0.04$.

\section{Impact of Hartmann Number:}

Figure 6 set out the results for Hartmann number $(\mathrm{H} a=0,10,20,50)$ with fixed $\phi=0.04$ and $R a=10^{5}$ on streamlines for three various (case I, case II, \& case III) updraft warmed boundary conditions. We see that for every $\mathrm{Ha}$, streamlines are smooth and the circulation is found nearly whole region within the enclosure and from a clockwise circled for uniformly warmed horizontal wall (case I). The deportments of the fluid within the enclosure become slow for case I, with regard to the applied magnetic force represented by Hartmann number takes care to slow down the fluid motion. But a small secondary counter clockwise 

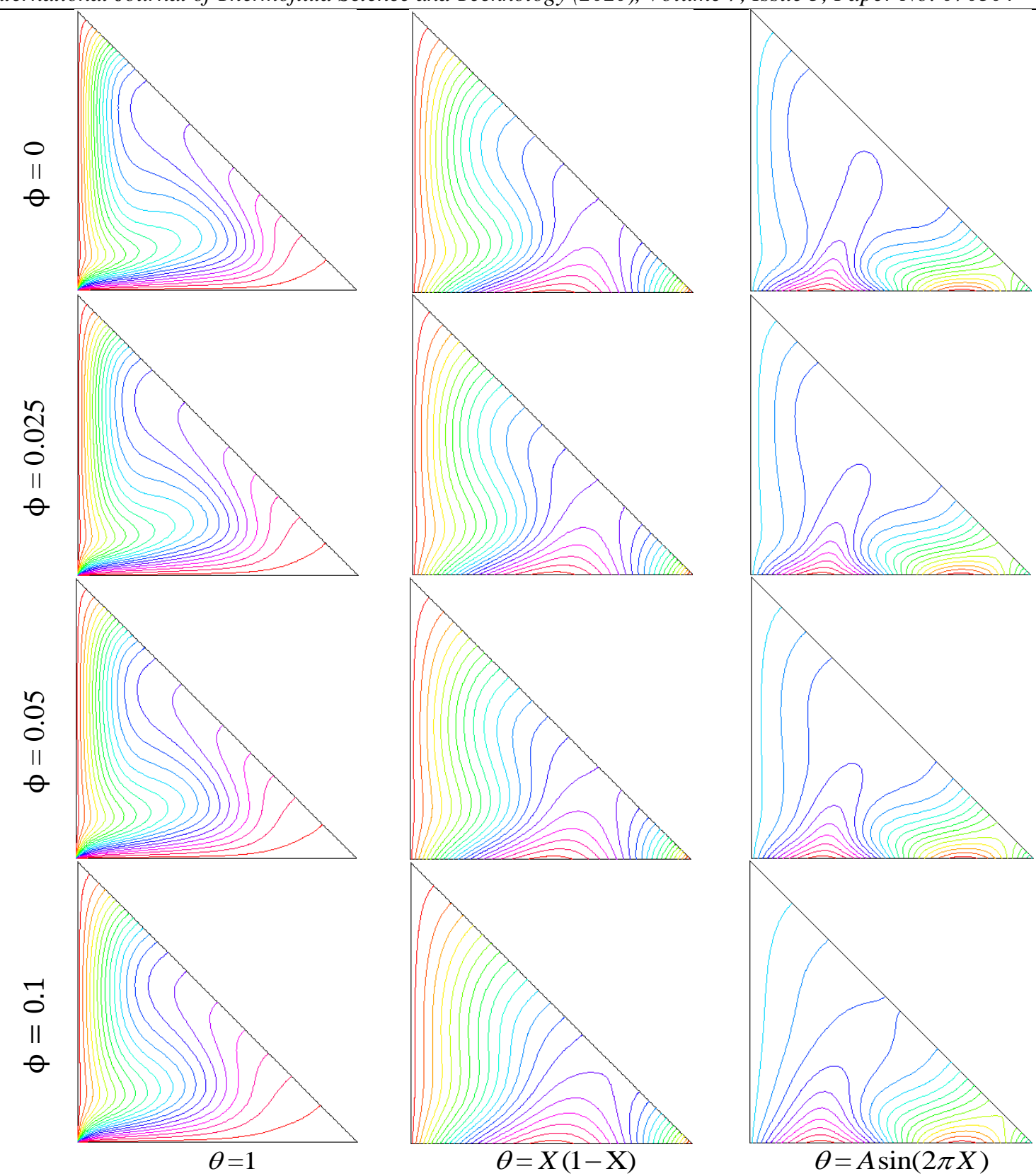

Fig. 8: Outcomes of nanoparticles volume fraction on isotherm contours for three various heated boundary conditions with fixed $R a=10^{5}$ and $H a=10$.

vortex is further noticed within the cavity for higher $\mathrm{Ha}$ in case II. This is due to the fact that the flow enlarges in the middle and this leads to create a secondary circulation inside the enclosure. For case III, the figures depict that there are two revolving vortices within the cavity concerning non-uniform heated boundary condition on the horizontal wall. This results indicate that fluid within enclosure taking more heat by horizontal hot wall endeavors to departure upward on account of the impact of buoyant force whilst comparatively cooler fluid neighbor the perpendicular wall refuge to horizontal hot wall. The mode of the streamline is alternated and flow strength within enclosure cut down for the augmentation of Hartmann number. The physical reasoning behind it that potential magnetic field produces a 
Tarikul Islam et al.

International Journal of Thermofluid Science and Technology (2020), Volume 7, Issue 3, Paper No. 070304

Lorentz force that has a characteristics of protesting to very of its propagation as weakens the streams within the enclosure.

The impact of the Hartmann number $(\mathrm{Ha}=0,10,20,50)$ on the distributions of isotherms for three different (Case I, Case II, Case III) updraft thermal boundary conditions with fixed $\phi=0.04$ and $R a=10^{5}$. The figures illustrate that isotherm lines are clustered neighbor the horizontal hot wall within enclosure for uniformly thermal boundary condition. The isotherms patter are more pronounced for the low Hartmann number $(\mathrm{H} a=0)$ which indicates the potential convection occurs for the non-appearance of magnetic field. For nonuniform heated boundary situation (case II), the dominance of Hartmann number stand nearly undistorted which depicts that $\mathrm{Ha}$ stay in the thermal field without creating any influence on the flow field. For sinusoidal thermal system (case III), the temperature gradient is completely weak in the upper region in the enclosure on account of the potential Lorentz force from Hartmann number abate the temperature distribution. Therefore, the rate of temperature transfer may be controlled using magnetic field into the nanofluid flow domain.

\section{Impact of nanoparticles volume fraction:}

The outcomes of $\phi(=0,0.025,0.05,0.1)$ on isotherm contours for three different (Case I, Case II, Case III) updraft thermal boundary conditions with fixed $\phi=0.04$ and $R a=10^{5}$ are displayed in Figure 8. These outcomes predicts the concept of the genre of temperature transfer and an indicator that how the temperature is diffused into fluid within the cavity. It is seen from these figure the streamlines are compact and almost collateral to each other neighbor the horizontal hot wall and perpendicular cold wall that reveal the mastery of conduction for temperature distribution. These figures also depicts that isotherm delineations are further compressed neighbor left-hand floor corner within cavity. The isotherm contours are compressed on standing wall alludes that temperature transfer proficiency unto perpendicular cooled wall from horizontal warmed wall. As increases $\phi$, distribution of isotherm contours quite evenly between horizontal hot and perpendicular cold walls within enclosure. Furthermore, higher thermal boundary thickness is noticed for uniform warmed system (case I) than non-uniform warmed system (case II \& case III). These figure also depicts that the isotherm contours become more packed in the case of uniform warmed system compare to non-uniformly thermal boundary conditions.

\section{Impact of Average Nusselt number:}

Figure 9, 10 and 11 demonstrate the effect of average Nusselt number for changing Rayleigh number $(\mathrm{Ra})$ against (a) Hartmann number $(\mathrm{Ha})$, (b) nanoparticles volume fraction $(\phi)$ using three several heated boundary systems (case I, case II, and case III). Average Nusselt number diminishes for increase of Hartman number in all three several warmed boundary system whereas increases for the augmentation of Rayleigh number. These figures exhibits that, for $R a=10^{4}$, the average rate of temperature transfer stay constant for the enhancement of Hartman number for all three distinct thermal boundary conditions. Rate of temperature transfer also enhances for the enhancement of $(\phi)$ for all three warmed-up boundary conditions. The additional nanoparticles enhances average rate of temperature flow. These figures also depict higher rate of temperature transfer is executed with uniformly warmed boundary conditions (case I) than non-uniformly thermal boundary conditions (case II \& case III). 
Tarikul Islam et al.

International Journal of Thermofluid Science and Technology (2020), Volume 7, Issue 3, Paper No. 070304

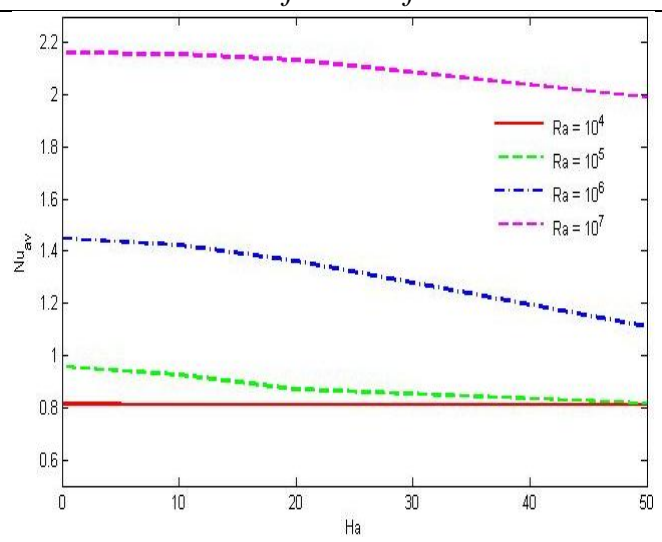

(a)

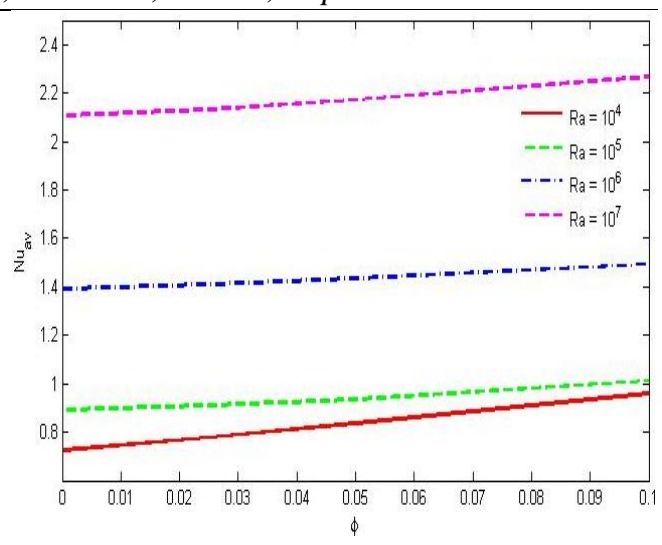

(b)

Fig. 9: Outcome of average Nusselt number of $R a$ against (a) $H a$, and (b) $\phi$ on uniformly heated horizontal wall (case I).

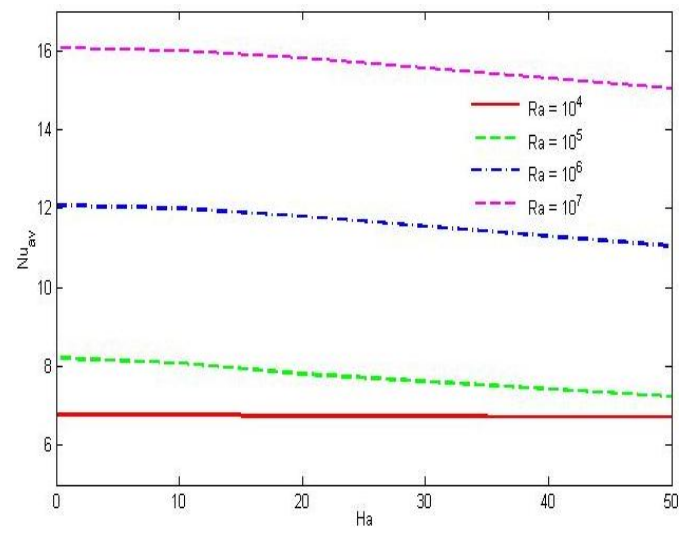

(a)

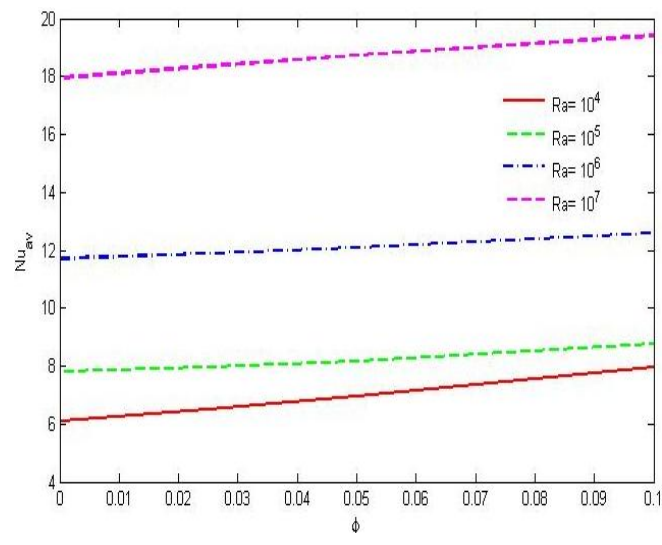

(b)

Fig. 10: Outcome of average Nusselt number of $R a$ against (a) $H a$, and (b) $\phi$ on nonuniformly heated horizontal wall (case II).

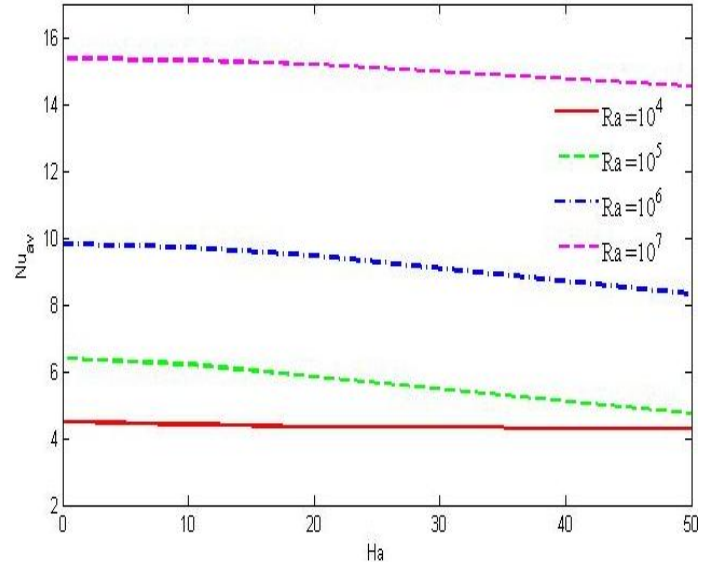

(a)

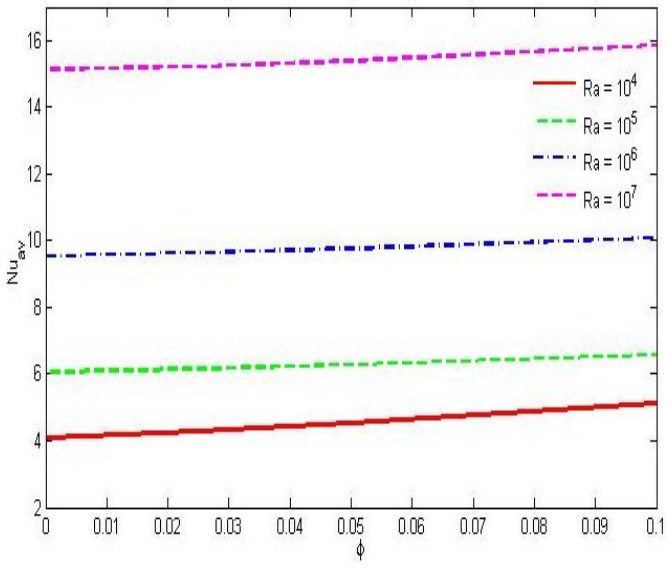

(b)

Fig. 11: Outcome of average Nusselt number of $R a$ against (a) $H a$, and (b) $\phi$ on nonuniformly heated horizontal wall (case III). 
Tarikul Islam et al.

International Journal of Thermofluid Science and Technology (2020), Volume 7, Issue 3, Paper No. 070304

\section{Conclusions:}

The time-independent temperature flow as well as fluid flowing of cupper-water nanofluid in right-angled triangular cavity taking into account three several thermal boundary systems is observed in current research. Galerkin weighted residual finite element analysis is employed for calculations. The impacts of various model parameter over the flow domain and temperature transfer are presented using streamlines, isotherms and average Nusselt number and interpreted them. The following central findings are listed:

i. Flow domain and temperature transfer rate significant change for the enhancement of Rayleigh number. The low buoyancy force reveal conduction whereas higher buoyancy force corresponds to convection.

ii. Better temperature transfer is conformed for upper Rayleigh number.

iii. Temperature transfer value diminishes for the potential magnetic effect whereas enhance with increment of nanoparticles volume fraction.

iv. Average Nusselt number is higher for uniformly warmed boundary condition (case I) than non-uniform warmed boundary condition (case II \& case III).

v. Average temperature transfer augmentation significantly depends on upper Rayleigh number and nanoparticles amount.

\section{Acknowledgements}

The authors are grateful to the editors, reviewers for their valuable comments.

\section{References:}

[1] Choi S., Nanofluid technology: current status and future research. Argonne IL: Energy Technology Division. Argonne National Laboratory, (1999) 604-639.

[2] Buongiorno J., Convective transport in nanofluids, ASME Journal of Heat Transfer, 128 (2006) 240-250.

[3] Aydin O., Ünal A., Ayhan T., Natural convection in rectangular enclosures heated from one side and cooled from the ceiling, International Journal of Heat and Mass Transfer 42 (1999) 2345-2355.

[4] Ghassemi M., Roux J.A., Shah R.K., Numerical investigation of natural convection within a triangular shaped enclosure, heat transfer in convective flows, New York, ASME, (1989) 169-75.

[5] Varol Y., Oztop H.F., Yilmaz T., Natural convection in triangular enclosures with protruding isothermal heater, International Journal of Heat and Mass Transfer, 50(1314) (2007) 2451-2462.

[6] Holtzman G.A., Hill R.W., Ball K.S., Laminar natural convection in isosceles triangular enclosures heated from below and symmetrically cooled from above, Journal Heat Transfer, 122 (2000) 485-91.

[7] Das S.K., Choi S.U.S., Yu W., and Pradeep T., (2007): Nanofluids: science and technology. New Jersey, USA, Wiley. 
Tarikul Islam et al.

International Journal of Thermofluid Science and Technology (2020), Volume 7, Issue 3, Paper No. 070304

[8] Roy S., Basak T., Thirumalesha C., and Krishna C.M., (2008): Finite element simulation on natural convection flow in a triangular enclosure due to uniform and non-uniform bottom heating. ASME Journal Heat Transfer, 130(3), 032501.

[9] Basak T., Roy S., Babu S.K., and Balakrishnan A.R., (2008): Finite element analysis of natural convection flow in an isosceles triangular enclosure due to uniform and nonuniform heating at the side walls. International Journal of Heat and Mass Transfer, 51(17-18), 4496-4506.

[10] Kent E.F., Numerical analysis of laminar natural convection in isosceles triangular enclosures for cold base and hot inclined walls, Mechanics Research Communication, 36 (2009) 497-508.

[11] Kamiyo O.M., Angeli D., Barozzi G.S., Collins M.W., Olunloyo V.O.S., Talabi S.O.A., Comprehensive review of natural convection in triangular enclosures, Applied Mechanics Review, 63 (2010) 060801-13.

[12] Wong K.V., De Leon O., Applications of nanofluids: current and future. Advances in Mechanical Engineering, 11 (2010) Article ID 519659.

[13] Saha, S.C., Unsteady natural convection in a triangular enclosure under isothermal heating, Energy Buildings, 43 (2011) 695-703.

[14] Aydin O., Yesiloz G., Natural convection in a quadrantal cavity heated and cooled on adjacent walls, ASME Journal of Heat Transfer, 133(5) (2011) 1-7.

[15] Walid A., Ahmed O., Buoyancy induced heat transfer and fluid flow inside a prismatic cavity, Journal of Applied Fluid mechanics, 3(2) (2012) 77-86.

[16] Nasrin R., Alim M.A., Chamkha A.J., Combined convection flow in triangular wavy chamber filled with water-CuO nanofluid: effect of viscosity models, International Communications in Heat and Mass Transfer, 39 (2012) 1226-1236.

[17] Khanafer K., Aithal S.M., Laminar mixed convection flow and heat transfer characteristics in a lid driven cavity with a circular cylinder, International Journal of Heat and Mass Transfer, 66 (2013) 200-209.

[18] Yesiloz G, Aydin O., Laminar natural convection in right-angled triangular enclosures heated and cooled on adjacent walls, International Journal of Heat and Mass Transfer, 60 (2013) 365-74.

[19] Bhardwaj S., Dalal A., Analysis of natural convection heat transfer \& entropy generation inside right-angled triangular enclosure, International Journal of Heat and Mass transfer, 65 (2013) 500-513.

[20] Suvash C. Saha, Gu Y.T., Natural convection in a triangular enclosure heated from below and non-uniformly cooled from top, International Journal of Heat and Mass Transfer, 80 (2015) 529-538.

[21] Mirabedin S.M., CFD modeling of natural convection in right-angled triangular enclosures, International Journal of Heat and Technology, 34(3) (2016) 503-506.

[22] Triveni M., Panua R., Sen D., Effects of variant positions of cold walls on natural convection in a triangular cavity, Journal of Applied Fluid Mechanics, 9(1) (2016) $185-193$. 
Tarikul Islam et al.

International Journal of Thermofluid Science and Technology (2020), Volume 7, Issue 3, Paper No. 070304

[23] Boulahia Z., Wakif A., Sehaqui R., Numerical investigation of mixed convection heat transfer of nanofluid in a lid driven square cavity with three triangular heating blocks, International Journal of Computer Applications, 143(6) (2016) 0975-8887.

[24] Rahman M.M., Alam M.S, Al-Salti N., Eltayeb I.A., Hydromagnetic natural convective heat transfer flow in an isosceles triangular cavity filled with nanofluid using two-component nonhomogeneous model, International Journal of Thermal Sciences, 107 (2016) 272-288.

[25] Siddiqui A.A., Turkyilmazoglu M., Natural convection in the ferrofluid enclosed in a porous and permeable cavity, International Communication in Heat and Mass Transfer, 113 ( 2020) 104499.

[26] Tiwari R.K., Das M.K., Heat transfer augmentation in a two-sided lid-driven differentially heated square cavity utilizing nanofluids, International Journal of Heat and Mass Transfer, 50 (2007) 2002-2018.

[27] Zienkiewicz O.C., Taylor R.L., The finite element method. 4th edition, McGraw-Hill. (1991).

[28] Gurkan Yesiloz, and Orhan Aydin, Laminar natural convection in right-angled triangular enclosures heated and cooled on adjacent walls, International Journal of Heat and Mass Transfer, 60 (2013) 365-374. 